\title{
Registro de cópula cruzada e concomitante em Phyllocaulis boraceiensis Thomé (Mollusca, Gastropoda, Veronicellidae) ${ }^{1}$
}

\author{
José Willibaldo Thomé ${ }^{2}$ \\ Rosane Souza da Silva ${ }^{2}$ \\ Suzete Rodrigues Gomes ${ }^{2}$ \\ lara Regina Cardoso Pitta ${ }^{2}$
}

\begin{abstract}
Record of the concomitant cross copulation by Phyllocaulis boraceiensis Thomé (Mollusca, Gastropoda, Veronicellidae). Two specimens of Phyllocaulis boraceiensis were found in concomitant cross copulation on 19.VII.1997. Each was in the "U"-shape position. Both specimens were the same age. One was $100 \mathrm{~mm}$. long and weighed $14.53 \mathrm{~g}$.; the other was $129 \mathrm{~mm}$ long and weighed $16.08 \mathrm{~g}$. Thirty-one days later the largest one laid 11 eggs; all hatched 64 days later. The other died in October, 1997 without laying.

KEY WORDS. Concomitant cross copulation, Phyllocaulis boraceiensis, Veronicellidae.
\end{abstract}

As espécies da família Veronicellidae são monóicas e a fecundação pode ser cruzada e concomitante ou alternada (THOMÉ 1968; MANSUR \& THOMÉ 1994), embora a autofecundação também já tenha sido constatada (Brites, comunicação pessoal).

Segundo THOMÉ (1972) Phyllocaulis boraceiensis tem sua distribuição restringida ao Brasil, nos Estados de São Paulo, Paraná, norte de Santa Catarina e sudeste de Minas Gerais, alcançando o maior comprimento $(180 \mathrm{~mm})$ dentro da família.

No Laboratório de Malacologia da Faculdade de Biociências, Pontifícia Universidade Católica do Rio Grande do Sul são mantidas várias espécies de Veronicellidae, em um vivário, equipado com aparelho de ar condicionado de 10.000 Btu's, cortinas espessas nas janelas e termo-higrômetro para registrar a temperatura (média de $20^{\circ} \mathrm{C}$ ) e umidade relativa do ar (média de $70 \%$ ). Os espécimes são mantidos em caixas de plástico, com tampa hermética, medindo $15,5 \mathrm{~cm}$ de comprimento por $10,5 \mathrm{~cm}$ de largura e com $6,0 \mathrm{~cm}$ de altura. Como substrato utiliza-se terra úmida esterilizada, com aproximadamente $1 \mathrm{~cm}$ de espessura. A alimentação consiste principalmente de cenoura e alface. A troca do alimento e limpeza das caixas é feita duas vezes por semana. Em cada caixa conserva-se, em geral, dois espécimes. No dia 19.VII.1997, às 11 h35min., encontrou-se dois espé-

1) Com bolsas e auxílios do CNPq, CAPES, FAPERGS, PUCRS.

2) Laboratório de Malacologia, Faculdade de Biociências, Pontifícia Universidade Católica do Rio Grande do Sul. Avenida Ipiranga 6681, prédio 12, salas 340 (30-37), 90619-900 Porto Alegre, Rio Grande do Sul, Brasil.

E-mail: thomejw@pucrs.br 

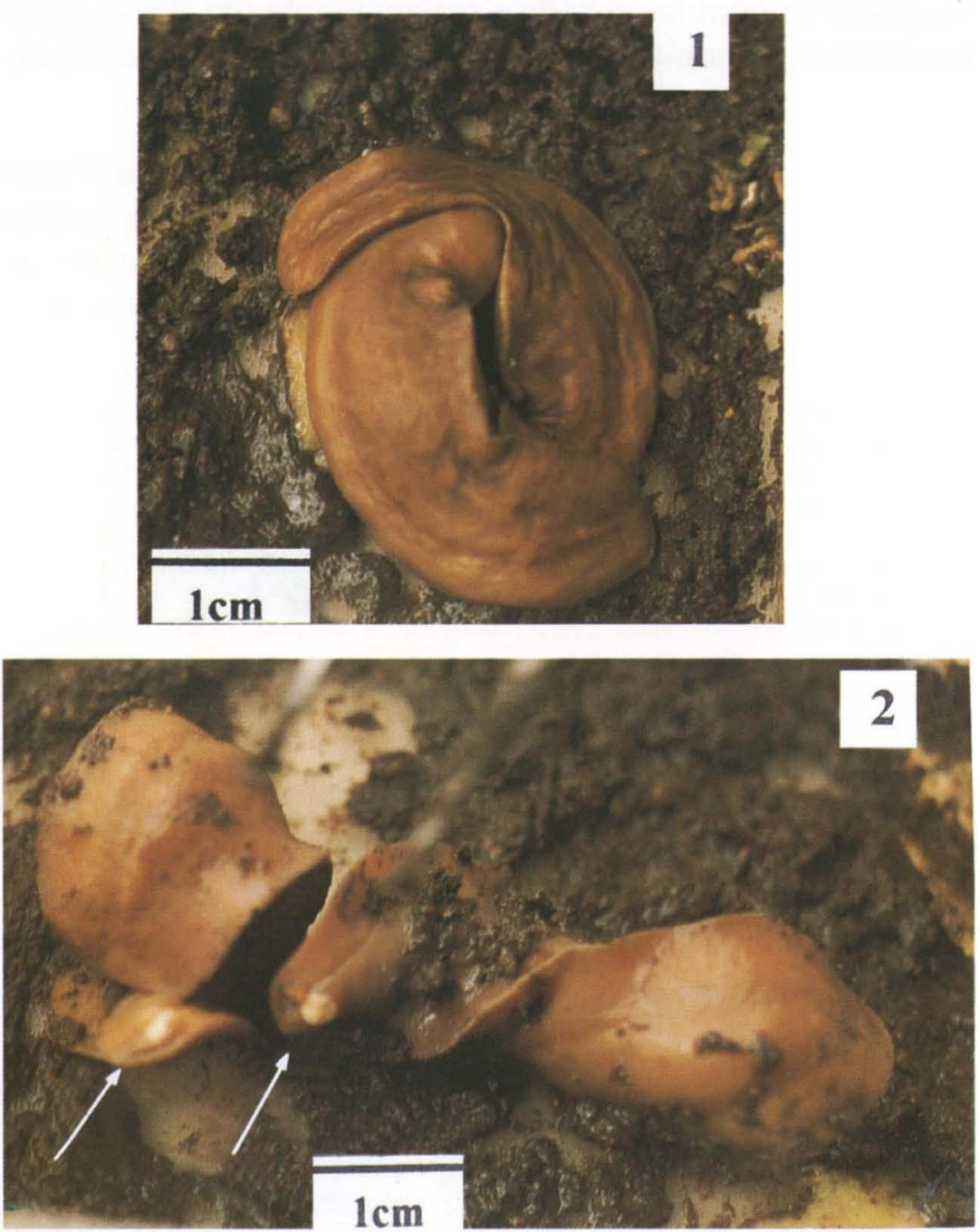

Figs 1-2. Phyllocaulis boraceiensis. (1) Vista dorsal dos dois espécimes, notando-se a posição em forma de "U"; (2) vista após manipulação, notando-se os respectivos pênis (setas), ainda não totalmente recolhidos.

cimes de $P$. boraceiensis em posição peculiar, indicativo de cópula cruzada e concomitante. Ambos os exemplares são provenientes de uma mesma postura, ocorrida no vivário e eclodida em 31.VII.1995. Com 23 meses e 18 dias, possuíam $100 \mathrm{~mm}$ e $129 \mathrm{~mm}$ de comprimento e $14,53 \mathrm{~g}$ e $16,08 \mathrm{~g}$ de peso, respectivamente.

Durante a cópula não se observou participação da glândula peniana, como já foi referido para P. soleiformis (Orbigny, 1835) (THомÉ 1968). 
A região do poro sexual masculino (anterior) de cada parceiro estava ajustada firmemente ao poro genital feminino do outro, assumindo, cada um dos animais, uma posição em forma de "U" (Fig. 1). Poucos minutos depois, talvez devido a manipulação, os animais desprenderam-se um do outro, encerrando as cópulas e afastando-se em direções opostas (Fig. 2). O comportamento durante a cópula foi semelhante ao constatado por THOMÉ (1968) para P. soleiformis, porém difere de Sarasinula linguaeformis (Semper, 1885), cujo cruzamento não é concomitante e os parceiros assumem uma posição em "T" (MANSUR \& THOMÉ 1994).

Após o acasalamento os espécimes foram mantidos separados, tendo o maior deles efetuado uma postura ovípara 31 dias depois (19.VIII.1997). Esta postura possuía 11 ovos e teve 100\% de eclosão, após incubação de 64 dias (22.X.1997). Não foi constatada até fevereiro de 1998 nova postura. O outro espécime morreu em outubro de 1997, não efetuando postura. A manipulação dos animais, durante a cópula, pode ter provocado interrupção antes da transferência do esperma. Constata-se que os animais podem atingir a maturidade com cerca da metade do comprimento máximo registrado para a espécie.

\section{REFERÊNCIAS BIBLIOGRÁFICAS}

Mansur, G. \& J.W. Thomé. 1994. Contribuição à biologia de Sarasinula linguaeformis (Semper, 1885) e Sarasinula plebeia (Fischer, 1868) (Veronicellidae, Gastropoda). Biociências, Porto Alegre, 2 (2): 39-48.

Thomé, J.W. 1968. Zur Biologie der Veronicellidae (Mollusca; Gastropoda). Beobachtungen über die Begattung und Eiablage. Arch. Molluskenk., Frankfurt, 98 (3/4): 143-149.

. 1972. Uma nova espécie de Phyllocaulis do Brasil (Veronicellidae, Gastropoda). Iheringia, Série Zoologia, Porto Alegre, (41): 59-68.

Recebido em 20.IV.1998; aceito em 09.VIII.1999. 